University of Wollongong

Research Online

Faculty of Engineering and Information

Faculty of Engineering and Information

Sciences - Papers: Part B

Sciences

2018

The effect of graphene on the yarn pull-out force and ballistic performance of Kevlar fabrics impregnated with shear thickening fluids

Zhuhua Tan

Hebei University of Technology, ztan@uow.edu.au

Weihua Li

University of Wollongong, weihuali@uow.edu.au

Wei Huang

Huazhong University of Science and Technology

Follow this and additional works at: https://ro.uow.edu.au/eispapers1

Part of the Engineering Commons, and the Science and Technology Studies Commons

Research Online is the open access institutional repository for the University of Wollongong. For further information contact the UOW Library: research-pubs@uow.edu.au 


\title{
The effect of graphene on the yarn pull-out force and ballistic performance of Kevlar fabrics impregnated with shear thickening fluids
}

\author{
Abstract \\ The ballistic performance of Kevlar fabric impregnated with different shear thickening fluids (STFs) were \\ investigated at various impact velocities. The $\mathrm{SiO}_{2}$ nanoparticle based STFs were reinforced with \\ graphene and showed a significant increase in viscosity and shear thickening efficiency compared to pure \\ STF. Ballistic experiments were performed on fabric treated by different STFs, and different failure modes \\ including yarn slipping, extraction, and breakage in shear failure were obtained. To better understand how \\ different STFs affect ballistic performance, single yarn pull-out tests were also carried out to examine the \\ shear strength and friction between the interlocking yarns of fabric treated with STF. The results showed \\ that STF reinforced with graphene is better at preventing the yarns from slipping, and the single yarn pull- \\ out force is almost 5 times more than pure STF. Moreover, reinforced STF also has a significant influence \\ on the ballistic limit and energy absorption of Kevlar fabrics. And the increased amplitude of energy \\ absorption is almost $20 \%$ more than the pure STF/Kevlar load case. Combining with the energy \\ absorption and different failure modes, the effect of STF on the failure mechanism of neat/treated fabric \\ was also discussed.

\section{Disciplines} \\ Engineering | Science and Technology Studies

\section{Publication Details} \\ Tan, Z., Li, W. \& Huang, W. (2018). The effect of graphene on the yarn pull-out force and ballistic \\ performance of Kevlar fabrics impregnated with shear thickening fluids. Smart Materials and Structures, \\ 27 (7), 075048-1-075048-10.
}




\title{
The effect of graphene on the yarn pull-out force and ballistic
} performance of Kevlar fabrics impregnated with shear thickening fluids

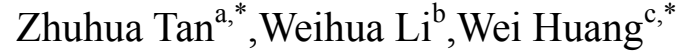 \\ ${ }^{a}$ School of Mechanical Engineering, Hebei University of Technology, Tianjin, 300401, China. \\ ${ }^{\mathrm{b}}$ School of Mechanical, Materials and Mechatronic Engineering, University of Wollongong, \\ Wollongong, NSW 2522, Australia. \\ ${ }^{\mathrm{c}} \mathrm{School}$ of Naval Architecture and Ocean Engineering, Huazhong University of Science and Technology, \\ Wuhan, 430074, China. \\ *Corresponding author. Email: zhtan@cqu.edu.cn(Z.H. Tan) and weihuanghust@hotmail.com(W. Huang)
}

Abstract: The ballistic performance of Kevlar fabric impregnated with different shear thickening fluids (STFs) were investigated at various impact velocities. The $\mathrm{SiO}_{2}$ nanoparticle-based STFs were reinforced with graphene and showed a significant increase in viscosity and shear thickening efficiency compared to pure STF. Ballistic experiments were performed on fabric treated by different STFs, and different failure modes including yarn slipping, extraction, and breakage in shear failure were obtained. To better understand how different STFs affect ballistic performance, single yarn pull-out tests were also carried out to examine the shear strength and friction between the interlocking yarns of fabric treated with STF. The results showed that STF reinforced with graphene is better at preventing the yarns from slipping, and the single yarn pull-out force is almost 5 times more than pure STF. Moreover, reinforced STF also has a significant influence on the ballistic limit and energy absorption of Kevlar fabrics. And the increased amplitude of energy absorption is almost $20 \%$ more than the pure STF/Kevlar load case. Combining with the energy absorption and different failure modes, the effect of STF on the failure mechanism of neat/treated fabric was also discussed.

Keywords: shear thickening fluid; yarn pull-out; ballistic performance; energy 
absorption; failure mode.

\section{Introduction}

Investigations on the impact resistance and energy absorption of armored woven fabric structures have attracted a great deal of interest in recent decades. Fabrics with high strength, high modulus, and excellent energy absorption such as Kevlar, Twaron, and Spectra [1-3] are extensively studied and employed in the armour systems. However, traditional body armour made of fabrics needs many layers to resist impact loadings, which reduces the flexibility and increases the weight. Recently, shear thickening fluid (STF) has been integrated into fabric to develop a soft and fluid armour that may satisfy the requirements of comfortable and lightweight body armour systems.

Shear thickening fluid (STF) is a dense colloid suspension, which exhibits the behavior of prompt increase in viscosity even to solid-like state under a certain shear rate, and then return to its original state when the load is removed. When fabrics treated by STF are subjected to stabbing or ballistic loading, the viscosity of STF in fabrics would increase dramatically. Part of the impact energy is dissipated through the increased viscosity of STF; further, the sliding of the fibers is also hindered by the STF in the fabrics, which promotes the energy absorption of the fabrics. Moreover, the flexibility of the impregnated fabric does not decrease because STF is a fluid at constant condition. It means that the specific properties of STF give it a wide application in body armour systems. 
A great deal of work has been done on the response and failure mechanism of fabric integrated with STFs. Some studies focused on the stab resistance and yarn pull-out behaviour of fabric impregnated with STF to analyse how STF affects the friction force between yarns[4-12]. Feng et al. [7] investigated the effect of size and type of nanoparticle on the stab resistance and yarn pull-out force of fabric treated with STF, while Gong et al. [8] studied the influence of the STF and the pull-out speed on pull-out force of Kevlar/STF fabrics. Furthermore, the ballistic performance of fabric treated by STF was also examined[13-22]; impregnated fabric impacted by a projectile at the velocity of $1.5 \mathrm{~km} / \mathrm{s}$ was studied experimentally and numerically byPark et al. [18-19], and results showed that the ballistic performance of impregnated fabric had improved due to the increased friction force between yarns attributed by STF. Haro et al. [21] investigated the penetration resistance of composite laminates consisting of an aluminum plate, epoxy, and fabrics treated with STF, and the effects of hybrid material configuration on energy dissipation were examined. Moreover, the mechanical properties of fabric integrated with STFs were also investigated [24-28]; for instance, Lu et al. [26-27] reported on the compressive behaviour of warp-knitted spacer fabrics impregnated with STFs at different strain rates by experimental and numerical methods, while Cao et al. [28] studied the dynamic response of Kevlar fabric impregnated with STFs using a split Hopkinson pressure bar.

All of the above work indicated that viscosity is the essential mechanical property of STF required for its applications. The viscosity and shear thickening efficiency of 
STFs rely on the hydrodynamic lubrication force [29-32], which is influenced by the material, size, and volume fraction of the nanoparticles [7,20]. Currently, some methods have been developed to improve the traditional nanoparticle based STF by adding nanoscale additives[33], such as carbon nanotubes [34,35], SiC nanowires [36], and nano-clays [37]. Moreover, Laha A. et al. [35] showed an obvious improvement in impact resistance of fabric impregnated with silica-Hal nanotube compounded STF compared to the pure STF. Based on these effective methods, more work should be done to develop novel STF with higher shear thickening behaviour and more efficient energy dissipation.

In the present paper, graphene was designed to reinforce $\mathrm{SiO}_{2}$ nanoparticle based STF, and the rheological properties were tested and compared with pure STF; then different STFs were used to impregnate Kevlar fabrics to improve the impact resistance. To analyse the reinforcement efficiency attributed by graphene, a single yarn pull-out test and ballistic experiments were carried out on Kevlar fabrics treated by different STFs. The role played by different STFs on hindering yarns from slipping at different pull-out speeds was analysed. Furthermore, the influence of the different STFs on the ballistic limit velocity, failure mode, and energy absorption was also discussed.

\section{Experimental procedures}

\subsection{Materials}

The STF used here consists of $\mathrm{SiO}_{2}$ nanoparticles and polyethylene glycol with 
amolecular weight of 400 (PEG400). The $\mathrm{SiO}_{2}$ sphere fabricated by the Stober method is approximately $300 \mathrm{~nm}$ in diameter, as shown in Fig. 1(a). According to the $\mathrm{SiO}_{2}$ volume fraction of $56 \%$, the mixture of $\mathrm{SiO}_{2}$ nanoparticles and PEG400 solvent were treated in a planetary ball mill for 2-3 hours, and then a specific amount of graphene (Graphene has 10-15 layers in thickness and $800 \mathrm{~nm}$ in length or width. It is a product of Jiangsu XF Nano Company, as shown in Fig. 1(b)) was dispersed by the ultrasonic method and added into pure STF to improve its rheological properties. To analyse how the graphene volume fraction affected the mechanical properties of STF, two different graphene volume fractions were prepared; the total volume fraction of the solid phase in STF is 56 vol.\%, as shown in Table 1.
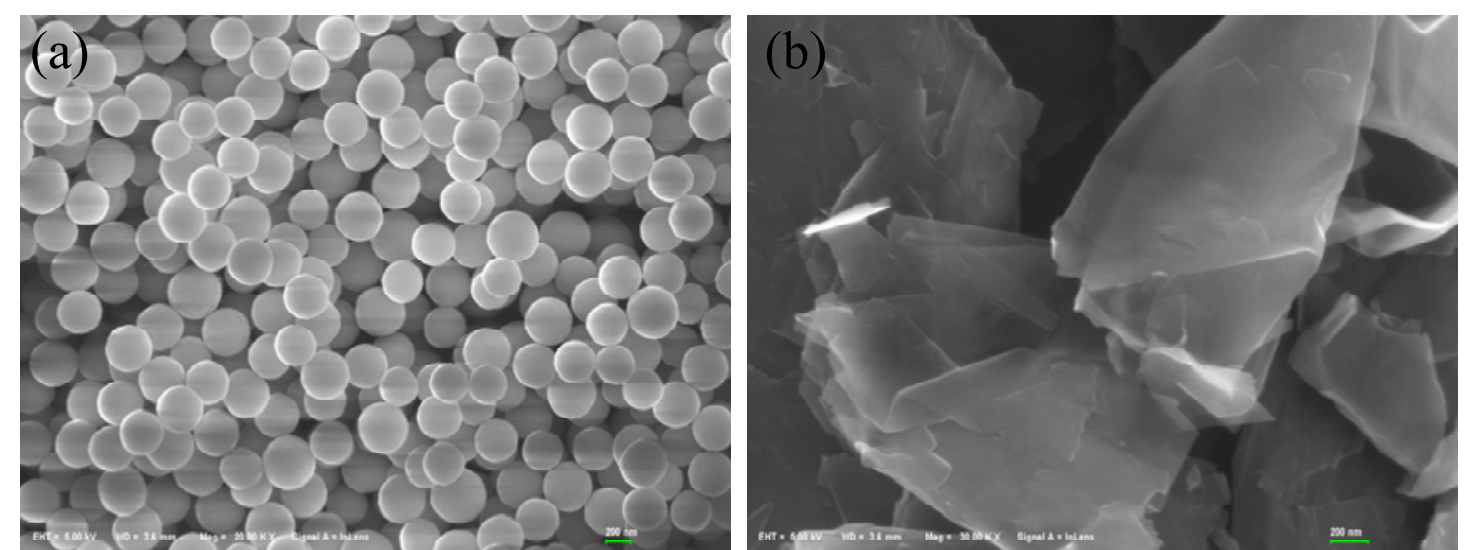

Fig. 1 SEM graph of solid phase in STFs. (a) $\mathrm{SiO}_{2}$ nanoparticle; (b) graphene.

Table 1 Volume fraction of solid phase in different STFs.

\begin{tabular}{lccc}
\hline \multicolumn{1}{c}{ Sample No. } & A & B & C \\
\hline Volume fraction of graphene (vol.\%) & 0 & 0.85 & 1.70 \\
Volume fraction of $\mathrm{SiO}_{2}$ (vol.\%) & 56 & 55.15 & 54.30 \\
\hline
\end{tabular}

The area density of plain woven aramid fabric used in this study is $198 \mathrm{~g} / \mathrm{m}^{2}$, and the linear density of yarns is 1100 denier. The procedure used to prepare fabric impregnated with STF is as follows: STF is diluted with ethanol to reduce its 
viscosity and then the fabric is immersed in diluted STF for 2-3 hours; The material is then removed and squeezed by a 2-roll mangle to remove extraSTF and then placed into an oven at $70^{\circ} \mathrm{C}$ for $2-3$ hours to remove the ethanol. The SEM graphs of the fabrics treated/untreated with STF are shown in Fig.,and it can be seen that the fibers are well coated with STF.
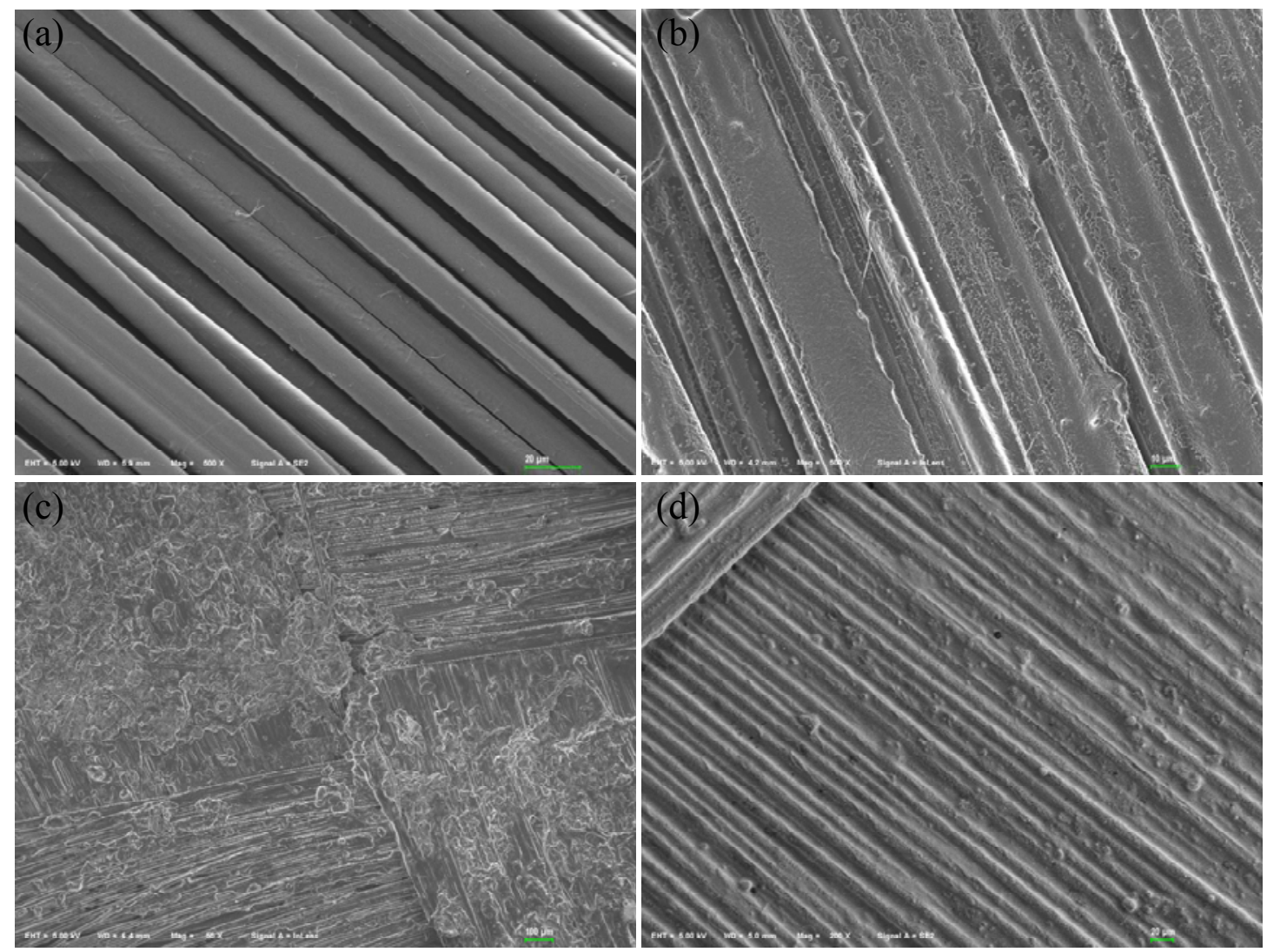

Fig. 2 SEM graph of fabric treated/untreated with STFs.(a) neat STF; (b)fabrictreated with STFs; (c) and (d) fabrictreated with reinforced STFs with graphene.

\subsection{Single yarn pull-out tests}

Single yarn pull-out tests were carried out on neat and treated fabric to evaluate the effect of the different STFs on the slippage behavior between yarns of the fabric. The experiments were carried out by using a universal testing machine (Instron Microtester 5848) at a tensile rate of 50,200, and $400 \mathrm{~mm} / \mathrm{min}$. The dimension of the 
Kevlar fabric sample is $100 \mathrm{~mm} \times 100 \mathrm{~mm}$, and it was fixed and pulled out in the warp and weft directions, respectively.The experimental configuration is shown in Fig. 3.

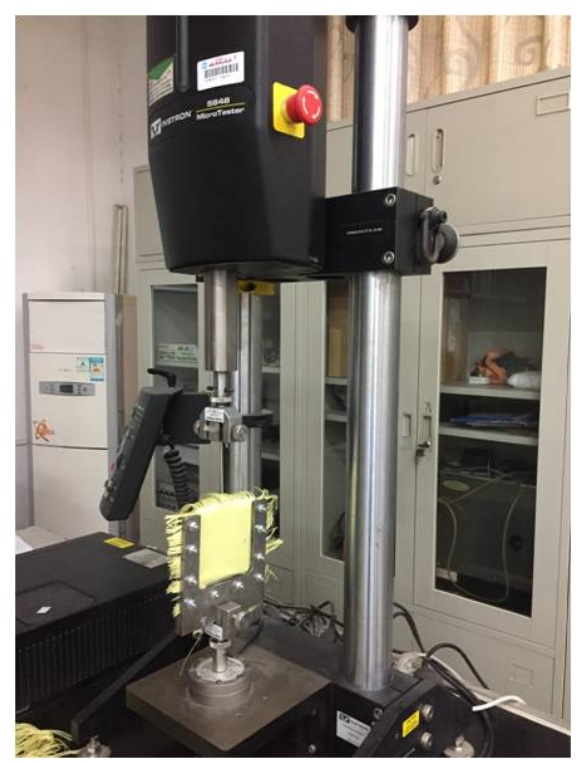

Fig. 3 The single yarn pull-out test configuration.

\subsection{Ballistic experiments}

A one-stage light gas gun was implemented to test the ballistic performance of the Kevlar fabrics untreated/treated with different STFs, as shown in Fig. 4. The steel cylindrical projectile is $\Phi 12 \mathrm{~mm} \times 28 \mathrm{~mm}$ and weighs $24.2 \mathrm{~g}$. In order to record the initial velocity and residual velocity of the projectile, two laser velocimeters were used and placed in front of and behind the specimen.

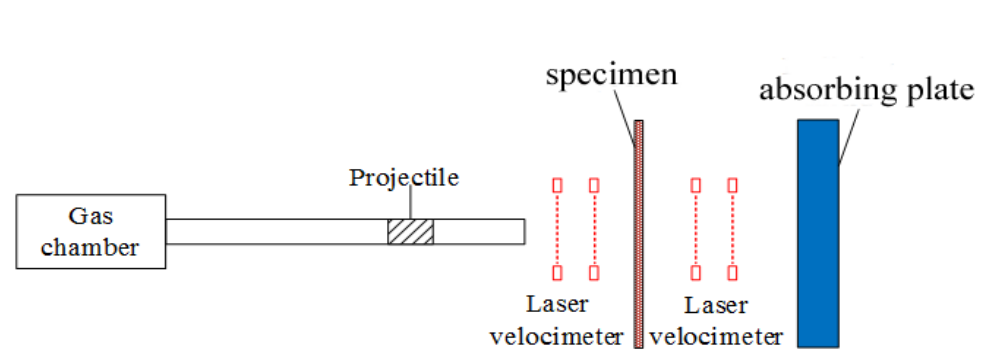

(a)

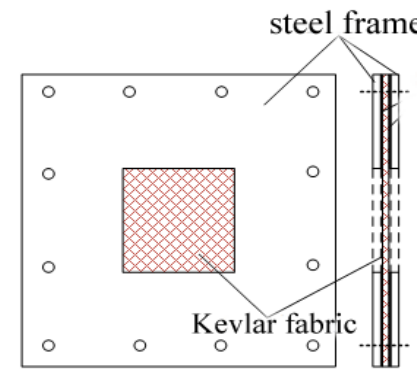

(b)

Fig. 4 Schematic of (a)the impact experimental setup, and (b) clamping condition. 
The Kevlar fabric specimens were impregnated with pure and reinforced STFs, respectively. And then the neat Kevlar fabric was also tested and compared to the impregnated fabric load cases. All the impact tests were carried out on a single layer of Kevlar fabric with a dimension of $260 \mathrm{~mm} \times 260 \mathrm{~mm}$. The fabric was fully clamped in a steel frame and the loading area of the specimen was $100 \mathrm{~mm} \times 100 \mathrm{~mm}$, as shown in Fig. 4(b).

\section{Results and Discussions}

\subsection{Rheological behaviour}

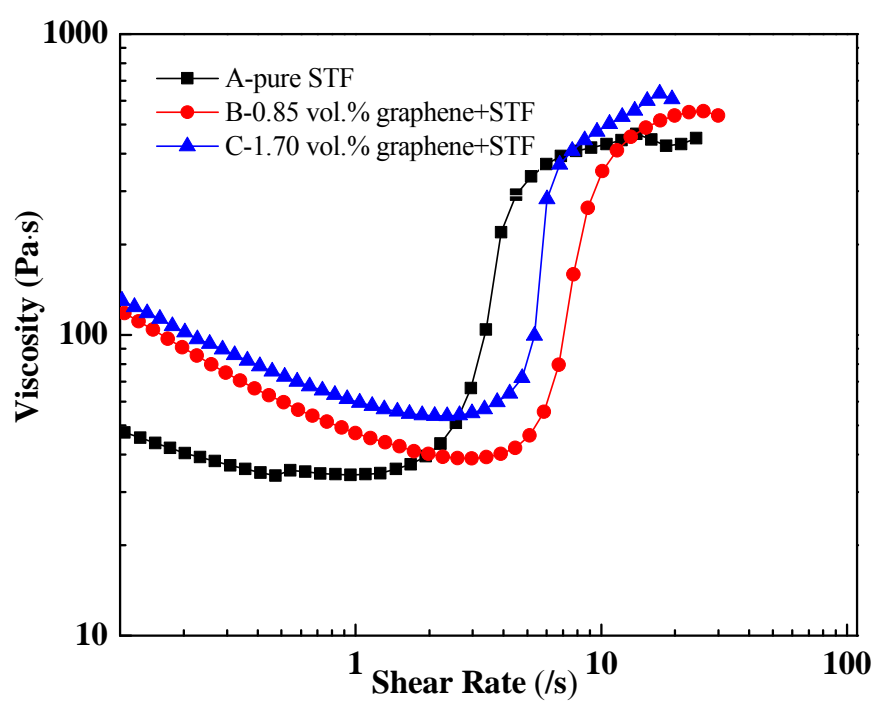

Fig. 5 Curves of viscosity-shear rates of samples A, B, and C.

The viscosities of STFs with/without graphene were tested at $25^{\circ} \mathrm{C}$ and shear rates of $10^{-3} \sim 100 / \mathrm{s}$ with a rheometer (Anton-Paar MCR301 at the University of Science and Technology of China). The curves of viscosity at different shear rates are shown in Fig. 5, which shows two phases of each curve - shear thinning and shear thickening. The viscosity of reinforced STF is much higher than pure STF, but at low shear rates the viscosity of STF reinforced with 0.85 and 1.70 graphene was almost $118 \mathrm{~Pa} \cdot \mathrm{s}$ and $130 \mathrm{~Pa} \cdot \mathrm{s}$, respectively, which is several times larger than pure STF but 
much smaller than the STF reinforced by SiC nanowires listed in Ref. [36]. This means that STF reinforced by graphene is easier to flow than STF reinforced by nanowires at a low shear rate. In the shear thickening phase, the maximum viscosities of STF with and without graphene are approximately $634 \mathrm{~Pa} \cdot \mathrm{s}$ and $465 \mathrm{~Pa} \cdot \mathrm{s}$, and the increase in amplitude is approximately $36 \%$. The mechanism of the traditional nanoparticle based shear thickening fluids is generally attributed to the hydrodynamic lubrication force and contact force among these nanoparticles[29-32]. However, our new STF included graphene as an additive. As the graphene can be considered as a plate shape, the hydrodynamic lubrication force in the reinforced STF would include three parts: between nanoparticles, between nanoparticle and graphene, and between graphenes. These three lubrication forces work together to contribute to the enhancement of the STF viscosity, as compared to the pure STF, as shown in Fig.5.

\subsection{The effect of different STFs on single yarn pull-out force}

The results of singleyarn pull-out tests of fabric with/without different STFs at various pull-out speeds are shown in Fig. 6, where each curve also includes the yarn uncrimping stage and the yarn translation stage [38]. In the uncrimping stage, the pull-out force reaches a peak point and then oscillates when the free end of the yarn is translated into each weft yarn in the translation stage.

At a given pull-out speed, there is a significant increase in the yarn pull-out force of fabrics treated with STF compared to neat fabric. Moreover, the pull-out force of fabric treated by graphene reinforced STF is more than that by pure STF; therefore 
graphene increases the pull-out force of the fabric. The peak pull-out force was $2.42 \mathrm{~N}$, $5.61 \mathrm{~N}, 7.51 \mathrm{~N}$ and $12.32 \mathrm{~N}$ for neat, pure STF, $0.85 \mathrm{vol} . \%$ graphene and 1.7 vol.\% for the graphene load cases, respectively. The pull-out force for the graphene-STF load case increased by factors of 5 and 2 for the neat and pure STF load cases. The pull-out force also has the similar increase tendency at pull-out speeds of 200 and $400 \mathrm{~mm} / \mathrm{min}$, as shown in Fig. 6(a)-(c). Moreover, the volume fraction of graphene also influences the pull-out force such that the larger the volume fraction of graphene, the larger the pull-out force.

It was also obvious that the pull-out force is influenced by the pull-out speed for STF-treated fabric, whereas the pull-out force for neat fabric was almost independent of the pull-out speed, as shown in Fig. 8(d) with a solid line and shape. A yarn pull-out test is a typical shear process between warp and weft yarns. The yarn of fabric treated with STFs is coated by STFs, as shown in Fig. 2. When the yarn was pulled out and the STF coating on the outside of the yarn was subjected to shear loading, the viscosity of STF would increase and hinder the yarn from slipping, which results in the increase of pull-out force.

The equation $E_{a b s o r b}=\int F d s$ was used to calculate the energy absorption of untreated and treated Kevlar fabrics, as shown in Fig. 6(d), with a hollow shape and dotted line. The tendency of energy absorption is similar to the peak pull-out force. 

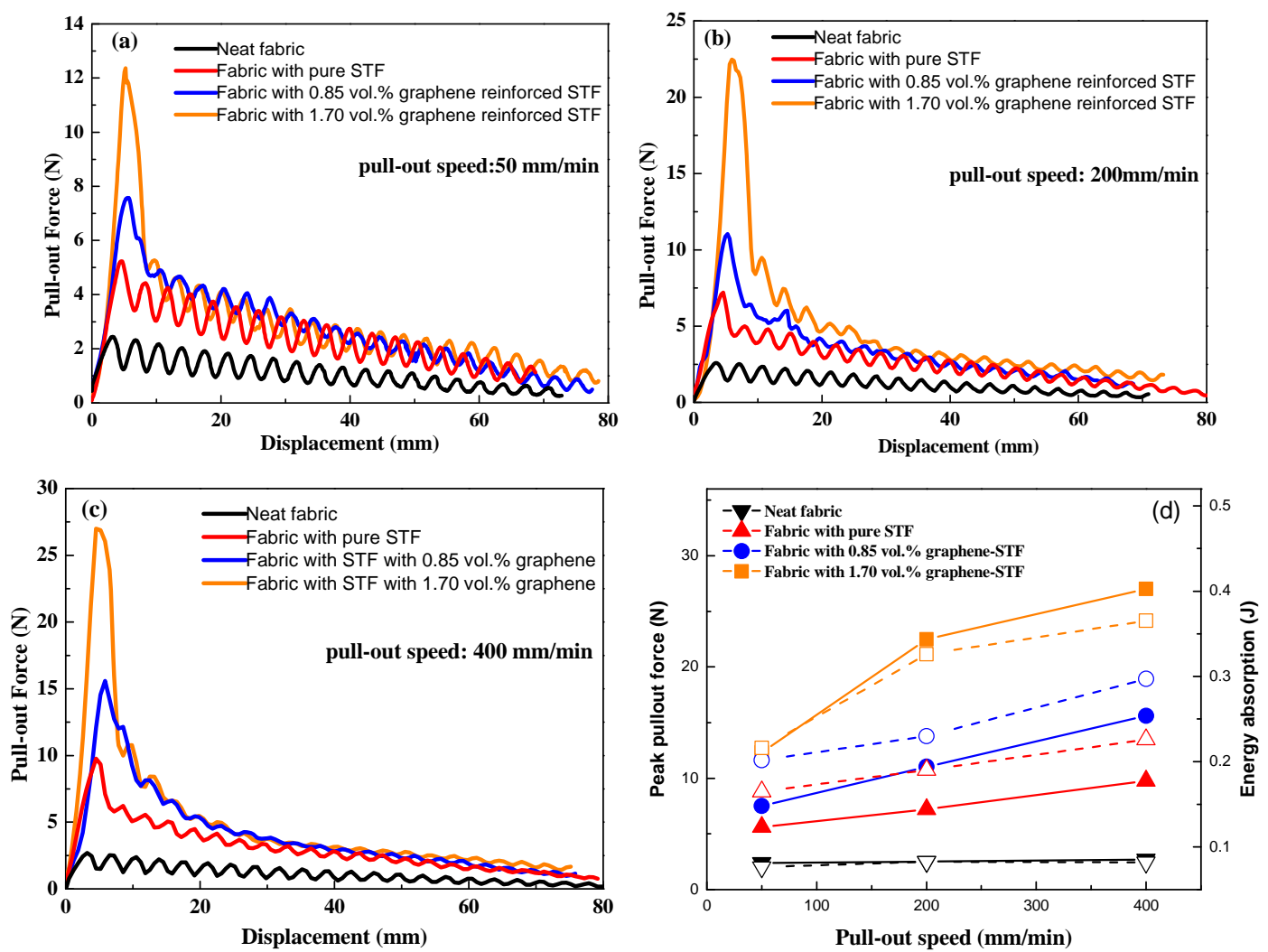

Fig. 6 Results of single yarn pull-out of neat and STF-treated fabric at various pull-out speeds. (a) $50 \mathrm{~mm} / \mathrm{min}$; (b) $200 \mathrm{~mm} / \mathrm{min}$; (c) $400 \mathrm{~mm} / \mathrm{min}$ and (d) peak pull-out forceand energy absorption.

In order to examine the effect of the STF on the peak value of the pull-out force, the efficiency factor of STF R was defined as:

$$
\mathrm{R}=\frac{F_{S T F}-F_{\text {neat }}}{F_{\text {neat }}}
$$

where $F_{\text {neat }}$ and $F_{\text {STF }}$ are the peak forces of fabric treated and untreated with STFs, respectively. At a pull-out speed of $50 \mathrm{~mm} / \mathrm{min}$, the value of $\mathrm{R}$ was $1.33,2.15$, and 4.13 for the corresponding STFs, but then R increased to 2.94, 5.37, and 10.12 at a pull-out speed of $400 \mathrm{~mm} / \mathrm{min}$, as shown in Fig. 7 . Pure STF can be considered as 0 vol.\% graphene reinforced STF. Graphene reinforced STF has an obvious effect on the pull-out force at a high pull-out speed than at a low pull-out speed; that is, the higher the volume fraction of graphene and the higher the pull-out speed, the better 
the efficiency of STF on the pull-out force.

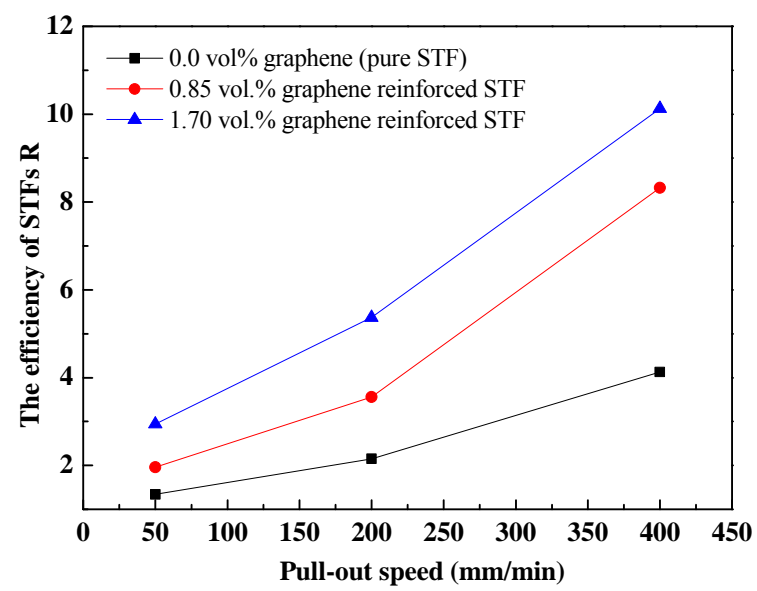

Fig. 7 The efficiency of STFs at different pull-out speeds.

\subsection{Ballistic performance of fabric treated with different STF}

\subsubsection{Residual velocity and energy absorption rate}

Table 2 The experimental results.

\begin{tabular}{|c|c|c|c|c|c|}
\hline No. & Load case & $\begin{array}{c}\text { Impact } \\
\text { velocity } \\
(\mathrm{m} / \mathrm{s})\end{array}$ & $\begin{array}{c}\text { Residual } \\
\text { Velocity } \\
(\mathrm{m} / \mathrm{s})\end{array}$ & $\begin{array}{c}\text { Energy } \\
\text { absorbed (J) }\end{array}$ & $\begin{array}{c}\text { Energy } \\
\text { absorption } \\
\text { rate }\end{array}$ \\
\hline 1 & neat Kevlar fabric & 28.3 & 0.0 & 9.69 & 1.00 \\
\hline 2 & neat Kevlar fabric & 29.2 & 0.0 & 10.32 & 1.00 \\
\hline 3 & neat Kevlar fabric & 34.3 & 0.0 & 14.24 & 1.00 \\
\hline 4 & neat Kevlar fabric & 37.4 & 14.4 & 14.42 & 0.85 \\
\hline 5 & neat Kevlar fabric & 41.9 & 25.9 & 13.13 & 0.62 \\
\hline 6 & neat Kevlar fabric & 51.6 & 34.5 & 17.81 & 0.55 \\
\hline 7 & neat Kevlar fabric & 64.4 & 52.6 & 16.71 & 0.33 \\
\hline 8 & neat Kevlar fabric & 89.1 & 84.7 & 9.25 & 0.10 \\
\hline 9 & pure STF/Kevlar fabric & 34.6 & 0.0 & 14.49 & 1.00 \\
\hline 10 & pure STF/Kevlar fabric & 35.5 & 0.0 & 15.25 & 1.00 \\
\hline 11 & pure STF/Kevlar fabric & 37.9 & 2.4 & 17.31 & 1.00 \\
\hline 12 & pure STF/Kevlar fabric & 54.5 & 36.7 & 19.64 & 0.55 \\
\hline 13 & pure STF/Kevlar fabric & 62.4 & 48.0 & 19.24 & 0.41 \\
\hline 14 & pure STF/Kevlar fabric & 84.0 & 66.9 & 31.22 & 0.37 \\
\hline 15 & pure STF/Kevlar fabric & 88.6 & 69.2 & 37.04 & 0.39 \\
\hline 16 & pure STF/Kevlar fabric & 93.41 & 76.5 & 34.77 & 0.33 \\
\hline 17 & graphene-STF/Kevlar fabric & 36.3 & 0.0 & 15.94 & 1.00 \\
\hline 18 & graphene-STF/Kevlar fabric & 37.3 & 0.0 & 16.83 & 1.00 \\
\hline 19 & graphene-STF/Kevlar fabric & 39.0 & 0.0 & 18.40 & 1.00 \\
\hline 20 & graphene-STF/Kevlar fabric & 41.4 & 5.8 & 20.33 & 0.98 \\
\hline 21 & graphene-STF/Kevlar fabric & 43.6 & 12.3 & 21.17 & 0.92 \\
\hline 22 & graphene-STF/Kevlar fabric & 52.3 & 24.2 & 26.01 & 0.79 \\
\hline 23 & graphene-STF/Kevlar fabric & 65.7 & 40.3 & 32.58 & 0.62 \\
\hline 24 & graphene-STF/Kevlar fabric & 81.7 & 52.5 & 47.42 & 0.59 \\
\hline
\end{tabular}




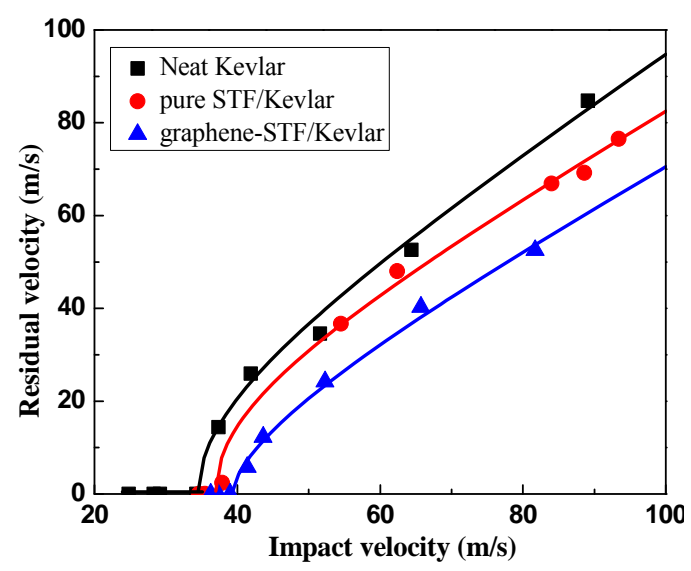

Fig. 8 The curves of residual velocity of the projectile at different impact velocities

The ballistic performance of fabric treated with different STFs was shown in Table 2. In order to analyze the ballistic performance of the fabric treated by different STFs, the corresponding impact and residual velocities were fitted by Recht-Ipson equation [39], as shown in Fig. 8. It can be seen from Fig. 8 that the ballistic limit velocities were $34.5 \mathrm{~m} / \mathrm{s}, 37.0 \mathrm{~m} / \mathrm{s}$, and $39.3 \mathrm{~m} / \mathrm{s}$ for neat Kevlar, pure $\mathrm{STF} / \mathrm{Kevlar}$, and graphene-STF/Kevlar fabrics, respectively. Compared to the ballistic limit of neat Kevlar fabrics, the ballistic limit of pure STF and graphene-STF load cases increased by $7.24 \%$ and $13.91 \%$. Moreover, the tendency of the residual velocity of graphene-STF load case was less than the neat fabric and pure STF load cases, which means that the graphene-STF load case had a high ballistic performance and energy absorption rate. 


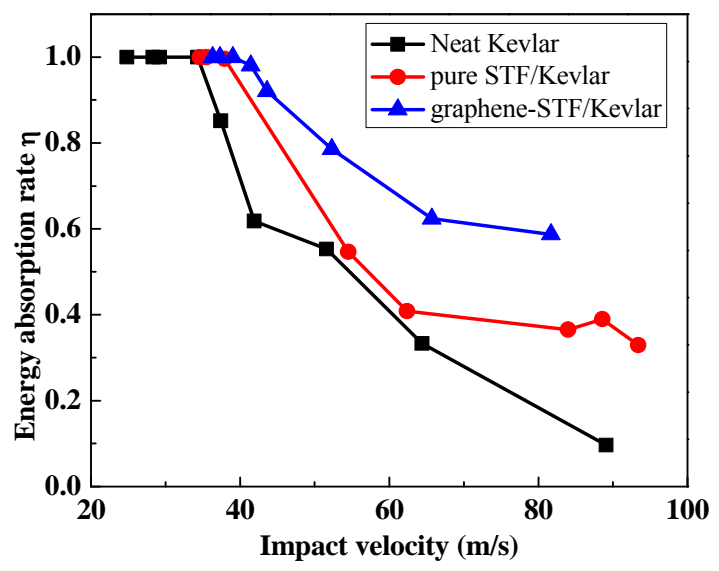

Fig. 9 The curves of the energy absorption ratio of STF to impact velocity.

To analyse the energy absorption of fabric during impact, the initial energy $E_{0}$ and the energy absorbed by the fabric $E_{\text {absorb }}$ were defined as follows:

$$
E_{0}=\frac{1}{2} m v_{0}^{2} \text { and } E_{\text {absorb }}=\frac{1}{2} m\left(v_{0}^{2}-v_{r}^{2}\right)
$$

wherem is the mass of the projectile, and $v_{0}$ and $v_{r}$ are the impact velocity and residual velocity. The energy absorption rate $\eta$ was defined as follows

$$
\eta=\frac{E_{a b s o r b}}{E_{0}}=1-\left(\frac{v_{r}}{v_{i}}\right)^{2}
$$

The effect of different STFs on the energy absorption rate of different Kevlar fabrics at various impact velocities was shown in Fig. 9. It is obvious that the energy absorption rate decreases as the impact velocity increases, which agrees with the varying tendency of residual velocity shown in Fig. 8. The energy absorption rate of the graphene-STF load case is larger than the neat fabric and pure STF load cases, whereas the absorption rate of neat Kevlar fabrics promptly decreased, while the graphene-STF load case did not. Particularly, when the impact velocity exceeded 80 $\mathrm{m} / \mathrm{s}$; here the absorption rate of graphene-STF/Kevlar, pure STF/Kevlar, and neat Kevlar were $58.7 \%(81.7 \mathrm{~m} / \mathrm{s}), \quad 36.6 \%(84.0 \mathrm{~m} / \mathrm{s})$ and $9.6 \%(89.1 \mathrm{~m} / \mathrm{s})$, respectively. Moreover, the tendency of the energy absorption rate of graphene STF was much 
higher than that of the neat fabric and pure STF load cases.

The residual velocity and energy absorption rate indicate that graphene-STF improved the ballistic performance of fabric efficiently, which is owing to the attribution by viscosity and shear thickening ability of graphene-STF. Combining with the results of single yarn pull-out experiments, the reasons we considered are as follows.

When projectiles impacted on the fabric, the impact stress can be expressed by $\sigma=\frac{(\rho c)_{1}(\rho c)_{2}}{(\rho c)_{1}+(\rho c)_{2}} v$, where $\sigma, \rho, c$, and $v$ are the impact stress, density, stress wave velocity, and impact velocity. When the impact stress is greater than the strength of the fabric, penetration and residual velocity occur, therefore, the greater the impact velocity was, the higher the impact stress was, which makes penetration be easier to occur and increases the residual velocity. It agrees well with the tendency shown in Fig. 8.

Furthermore, for the neat fabric load case, at a high impact velocity, the local impact pressure is greater than the strength of the yarn, which induces the local failure at the impact point and large residual velocity, and therefore the energy absorption rate decreased sharply. However, for fabric treated by different STFs, part of the impact energy was dissipated by STF by shear thickening, while the remaining impact energy was absorbed as the yarn deformed. Since the yarns of the fabric are coupled by STF, it makes more yarns bear they bore the impact loading collectively, which is different from the neat fabric load case. The shear thickening efficiency of graphene-STF is much better than pure STF, so the ballistic performance of 
graphene-STF load case is better than the neat and pure STF load cases.

\subsubsection{Failure modes of fabrics treated by different STFs}

Figure 10 illustrated the failure modes of neat Kevlar fabrics at different impact velocities. At the impact velocity of $41.9 \mathrm{~m} / \mathrm{s}$, the amount of yarn slipping and extraction at the failure zone has created a window in the fabric, but when the impact velocity increased to $89.1 \mathrm{~m} / \mathrm{s}$, there is a distinct window in the impact zone due to yarns breaking and expanding. The fabric also bulges due to inertial efficiency. At low impact velocity, the projectile impacts on neat fabric, the impact stress is less than the strength of the yarn, but the impact force causes the yarns to extract to make a window, as shown in Fig. 10(a)-(b); as the velocity increases, the impact pressure exceeds the strength of the yarn and the yarns expand and then break, which results in a window, as shown in Fig. 10(c)-(d).

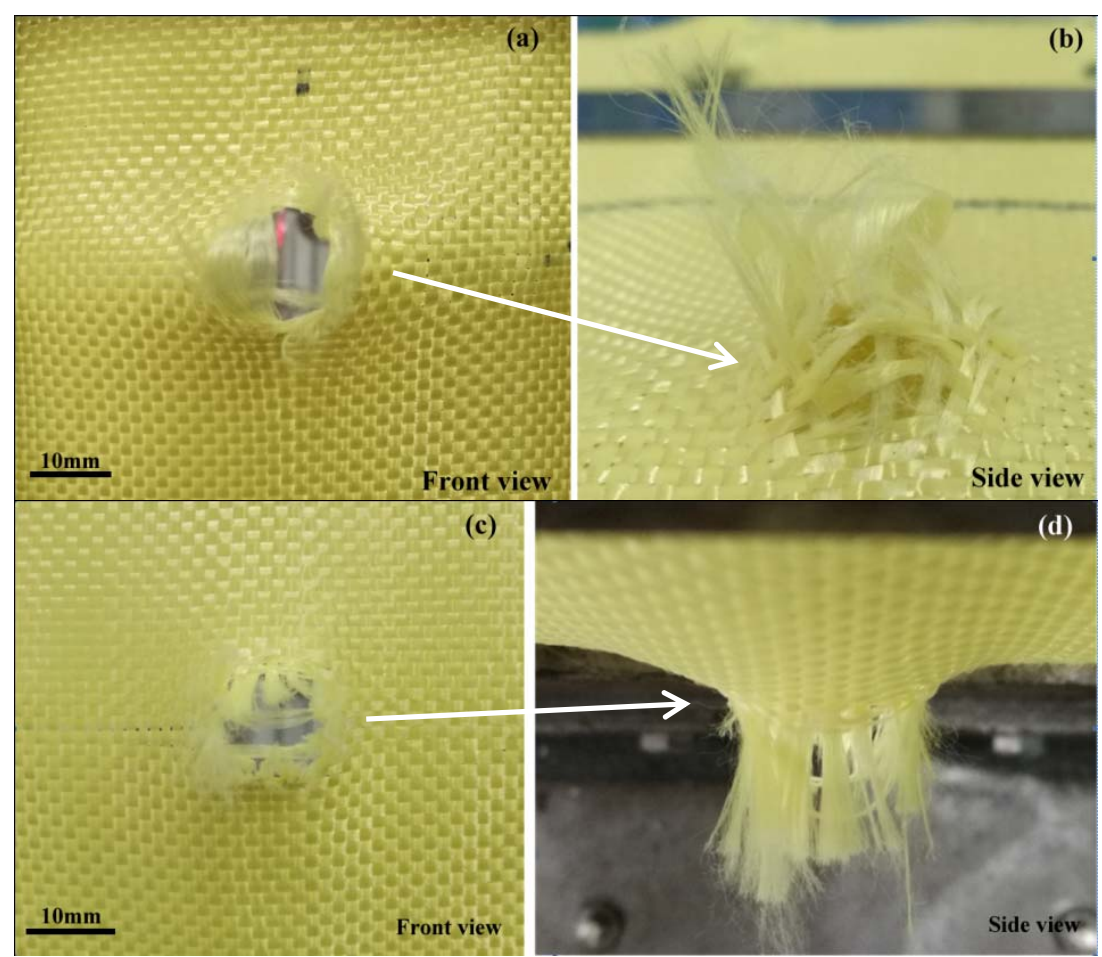

Fig. 10 Failure modes of neat Kevlar fabric at an impact velocity of (a)-(b) $41.9 \mathrm{~m} / \mathrm{s}$ 


$$
\text { and (c)-(d) } 89.1 \mathrm{~m} / \mathrm{s} \text {. }
$$

The dominant failure mode of fabrics treated with different STFs is shear failure, as shown in Fig. 11, which is unlike the neat fabric load cases. The yarns have almost no slipping and extraction. Since yarns consist of fibres, STF fills the fibres and yarns of the impregnated fabric, so when a projectile impacts on the treated fabric, the fibres and yarns are coupled by the shear thickening ability of STF, to the extent whereby it is essentially an integrated structure. At the impact zone shown in Fig. 11, yarn breakage in shear failure and window are the result of high impact pressure; therefore, the higher the viscosity of STF, the higher the friction force, which makes the fabric integrate more efficiently. It can be seen from Fig. 11 (c) and (d), graphene-STF makes a clear window in the fabric, which shows a better integration. And it also means an excellent energy absorption and ballistic performance. Majumdar A. et al. [40-41] have shown the yarn pull-out for untreated fabric load case and yarn rapture for treated fabric load case. The STF played the role of a bridge matrix which makes the yarns be integrated as a network to bear the impact loading, whereas only primary yarns in untreated fabric participate to resist the impact loading. Thus, more energy was absorbed by treated fabric than untreated fabric as shown in Table 2, which was also agreement with the results in [40-41]. 


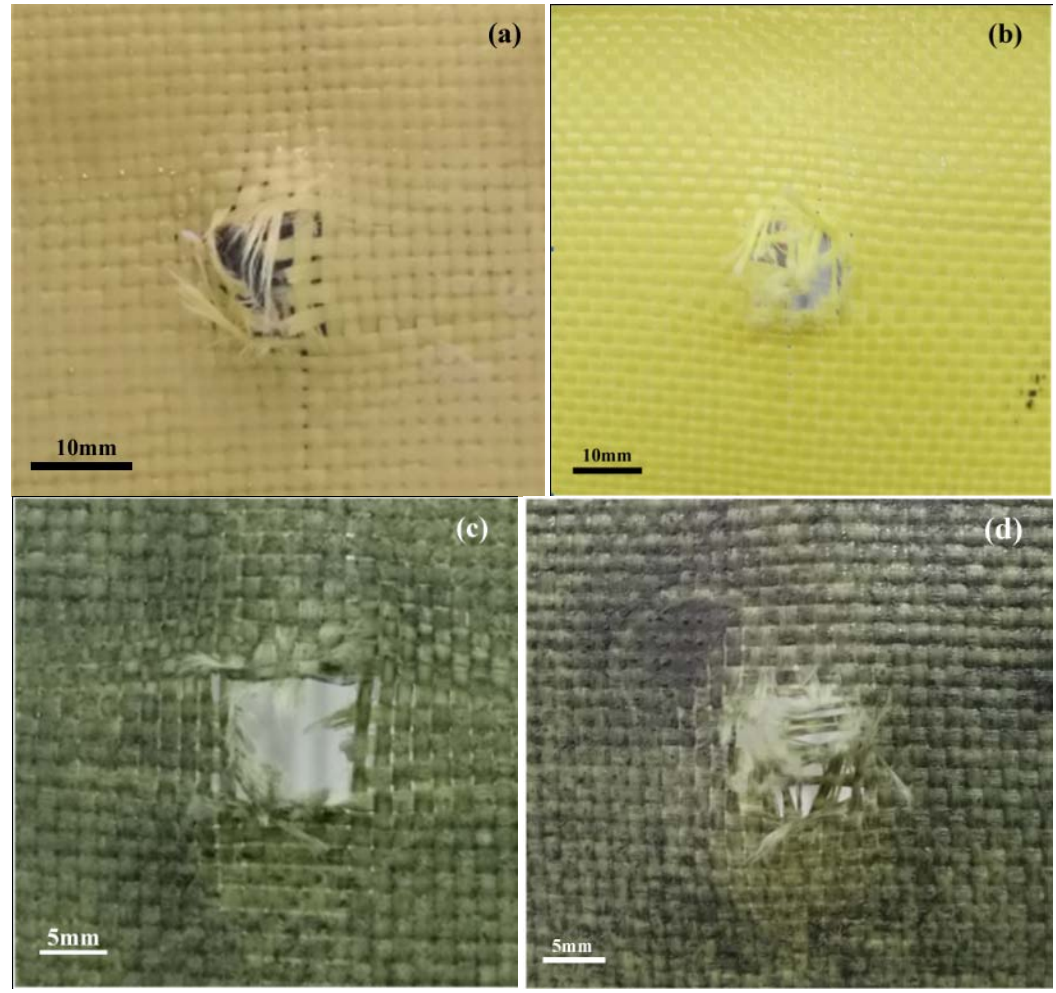

Fig. 11 Failure modes of pure STF/fabric (a)-(b) and graphene STF/fabric (c)-(d) at an impact velocity of (a) $37.9 \mathrm{~m} / \mathrm{s}$, (b) $84.0 \mathrm{~m} / \mathrm{s}$, (c) $37.3 \mathrm{~m} / \mathrm{s}$, and (d) $81.7 \mathrm{~m} / \mathrm{s}$.

\section{Conclusions}

In this paper, graphene was proposed to reinforce pure STF to improve the viscosity and shear thickening efficiency, and the ballistic performance of the fabric treated by the reinforced STF was also investigated and compared to the neat and pure STF load cases. The rheological behavior showed that graphene-STF improved the ability of STF to thicken more efficiently than pure STF. The maximum viscosities of reinforced STF increased the viscosity of pure STF from $465 \mathrm{~Pa} \cdot \mathrm{s}$ to $634 \mathrm{~Pa} \cdot \mathrm{s}$, the increase amplitude is approximately $40 \%$.

To study the attribution made by different STFs to the ballistic performance of impregnated Kevlar fabrics, single yarn pull-out tests and ballistic experiments were 
carried out on Kevlar fabrics. Typical yarn extraction, slippage, and breakage in shear fracture failure were obtained. Due to higher viscosity and shear thickening efficiency, graphene-STF improves the single yarn pull-out force of fabric by approximately $500 \%$ and $300 \%$ more than the neat fabric and pure STF load cases. The increased interaction between the yarns of graphene-STF/Kevlar fabrics results in a coupling integration of the yarns of the fabric, which enables more yarns to join together to resist external impact loading. Moreover, graphene-STF in the impregnated fabric can dissipate the energy through a transition of shear thickening due to its excellent rheological properties. This paper provides a valid method to develop a new type of STF using graphene, which can improve the ballistic performance of fabric better than pure STF.

\section{Acknowledgment}

This work is supported by the National Natural Science Foundation of China (No.11672214) and the Fundamental Research Funds for the Central Universities, Wuhan University of Technology (WUT: 2017IB008).

\section{References}

[1] Iremonger MJ and Went AC 1996 Ballistic impact of fibre composite armours by fragment simulating projectiles Compos. Part A 27A 575-81.

[2] Mouritz AP 2001 Ballistic impact and explosive blast resistance of stitched composites Compos. Part B 32 431-9. 
[3] Hosur MV, Vaidya UK, Ulven C and Jeelani S 2004 Performance of stitched/unstitched woven carbon/epoxy composites under high velocity impact loading Compos. Struct. 64 455-66.

[4] Decker MJ, Halbach CJ, Nam CH, Wagner WJ and Wetzel ED 2007 Stab resistance of shear thickening fluid (STF)-treated fabrics, Compos. Sci. Technol. $67565-78$.

[5] Kalman DP, Merrill RL, Wagner NJ and Wetzel ED 2009 Effect of particle hardness on the penetration behavior of fabrics intercalated with dry Particles and concentrated particle fluid suspensions Appl. Mater. Interfaces 1 2602-12.

[6] Hassan TA, Rangari VK and Jeelani S 2010 Synthesis, processing and characterization of shear thickening fluid (STF) impregnated fabric composites Mater. Sci. Eng. A 527 2892-9.

[7] Feng XY, Li SK, Wang Y, Wang YC and Liu JX 2014 Effects of different silica particles on quasi-static stab resistant properties of fabrics impregnated with shear thickening fluids Mater. Design 64 456-61.

[8] Gong XL, Xu YL, Zhu W, Xuan SH, Jiang WF and Jiang WQ 2014 Study of the knife stab and puncture-resistant performance for shear thickening fluid enhanced fabric J. Compos. Mater. 48: 641-57.

[9] Fahool M and Sabet AR 2016 Parametric study of energy absorption mechanism in Twaron fabric impregnated with a shear thickening fluid Int. J. Impact Eng. 90 $61-71$.

[10]Cwalina CD, McCutcheon CM, Dombrowski RD and Wagner NJ 2016 
Engineering enhanced cut and puncture resistance into the thermal micrometeoroid garment (TMG) using shear thickening fluid (STF) Armor ${ }^{\mathrm{TM}}$ absorber layers Compos. Sci. Technol. 131 61-6.

[11] Gürgen S and Kushan MC 2017 The stab resistance of fabrics impregnated with shear thickening fluids including various particle size of additives Compos. Part A 94 50-60.

[12] Xu Y, Chen XG, Wang Y and Yuan ZS 2017 Stabbing resistance of body armour panels impregnated with shear thickening fluid Compos. Struct. 163 465-73.

[13]Lee YS, Wetzel E.D and Wagner NJ 2003 The ballistic impact characteristics of Kevlar ${ }^{\circledR}$ woven fabrics impregnated with a colloidal shear thickening fluid $J$. Mater. Sci. 38 2825-33.

[14] Tan VBC, Tay TE and Teo WK 2005 Strengthening fabric armour with silica colloidal suspensions Int. J. Solids Struct. 42 1561-76.

[15]Park JL, Yoon BI, Paik JG and Kang TJ 2011 Ballistic performance of p-aramid fabrics impregnated with shear thickening fluid; Part I - Effect of laminating sequence, Text Res. J. 86 527-41.

[16]Park JL, Yoon BI, Park JG and Kang TJ 2012 Ballistic performance of p-aramid fabrics impregnated with shear thickening fluid; Part II - Effect of fabric count and shot location, Text Res. J. 82 542-57.

[17]Lee BW and Kim CG 2012 Computational analysis of shear thickening fluid impregnated fabrics subjected to ballistic impacts. Adv. Compos. Mater. 21 177-92. 
[18]Park Y, Kim Y, Baluch AH and Kim C 2014 Empirical study of the high velocity impact energy absorption characteristics of shear thickening fluid (STF) impregnated Kevlar Int. J. Impact Eng. 72 67-74.

[19]Park Y, Kim Y, Baluch AH and Kim C 2015 Numerical simulation and empirical comparison of the high velocity impact of STF impregnated Kevlar fabric using friction effects. Compos. Struct. 125 520-9.

[20]Petel OE, Ouellet S, Loiseau J, Frost DL and Higgins AJ 2015 A comparison of the ballistic performance of shear thickening fluids based on particle strength and volume fraction Int. J. Impact Eng. 85 83-96.

[21] Haris A, Lee HP, Tay TE and Tan VBC 2015 Shear thickening fluid impregnated ballistic fabric composites for shock wave mitigation Int. J. Impact Eng. 80 $143-51$

[22] Haro EE, Szpunar JA and Odeshi AG 2016 Ballistic impact response of laminated hybrid materials made of 5086-H32 aluminum alloy, epoxy and Kevlar® fabrics impregnated with shear thickening fluid Compos. Part A 87 54-65.

[23]Fischer C, Braun SA, Bourban PE, Michaud V, Plummer CJG and Manson JAE 2006 Dynamic properties of sandwich structures with integrated shear thickening fluids Smart Mater. Struct. 15 1467-75.

[24]Neagu RC, Bourban PE and Manson JAE 2009 Micromechanics and damping properties of composites integrating shear thickening fluids Compos. Sci. Technol. $69515-22$.

[25] Na W, Ahn H, Han S, Harrison P, Park JK and Jeong E 2016 Shear behavior of a 
shear thickening fluid-impregnated aramid fabrics at high shear rate. Compos. Part B 97 162-75.

[26] Lu ZQ, Jing XY, Sun BZ and Gu BH 2013 Compressive behaviors of warp-knitted spacer fabrics impregnated with shear thickening fluid Compos. Sci. Technol. 88 184-9.

[27] Lu ZQ, Wu LW, Gu BH, Sun BZ 2015 Numerical simulation of the impact behaviors of shear thickening fluid impregnated warp-knitted spacer fabric Compos. Part B 69 191-00

[28]Cao SS, Chen Q, Wang YP, Xuan SH, Jiang WQ and Gong XL 2017 High strain-rate dynamic mechanical properties of Kevlar fabrics impregnated with shear thickening fluid Compos. Part A 100 161-9.

[29] Waitukaitis SR and Jaeger HM 2012 Impact-activated solidification of dense suspensions via dynamic jamming fronts Nature 487 205-9.

[30]Lin NYC, Guy BM, Hermes M, Ness C, Sun J, Poon WCK and Cohen I 2015 Hydrodynamic and contact contributions to continuous shear thickening in colloidal suspensions Phys. Rev. Lett. 115228304.

[31]Majumdar S, Peters IR, Han E and Jaeger HM 2017 Dynamic shear jamming in dense granular suspensions under extension Phys. Rev. E 95012603.

[32] Comtet J, Chatte G, Nigues A, Bocquet L, Siria A and Colin A 2017 Pairwise frictional profile between particles determines discontinuous shear thickening transition in non-colloidal suspensions Nature Commun. 815633.

[33] Gürgen S, Kuşhan MC and Li WH 2016 The effect of carbide particle additives on rheology of shear thickening fluids Korea-Aust. Rheol. J. 28(2), 121-8. 
[34]Hasanzadeh M, Mottaghitalab V, Babaei H and Rezaei M 2016 The influence of carbon nanotubes on quasi-static puncture resistance and yarn pull-out behavior of shear-thickening fluids (STFs) impregnated woven fabrics Compos. Part A 88 263-71.

[35]Laha A and Majumdar A 2016 Shear thickening fluids using silica-halloysite nanotubes to improve the impact resistance of p-aramid fabrics Appl. Clay Sci. $132-133468-74$.

[36] Tan ZH, Ge JH, Zhang H, Zhai PC and Li WH 2017 Dynamic response of shear thickening fluid reinforced with $\mathrm{SiC}$ nanowires under high strain rates Appl. Phys. Lett. 111031902.

[37] Singh M, Mehta R, Verma SK and Biswas I 2017 Effect of addition of different nano-clays on the fumed silica-polyethylene glycol based shear-thickening fluids Mater. Res. Express 5(1) 014001.

[38]Zhu D, Soranakom C, Mobasher B and Rajan SD 2011 Experimental study and modeling of single yarn pull-out behavior of kevlar ${ }^{\circledR} 49$ fabric Compos. Part A $42868-79$.

[39]Recht RF and Ipson TW 1963 Ballistic Perforation Dynamics J. Appl. Mech. 30 384.

[40] Majumdar A, Butola BS and Srivastava A 2013 An analysis of deformation and energy absorption modes of shear thickening fluid treated Kevlar fabrics as soft body armour materials Mater Design 51 148-53.

[41]Laha A and Majumdar A 2016 Interactive effects of p-aramid fabric structure and shear thickening fluid on impact resistance performance of soft armor materials Mater Design 89 286-93. 